\title{
EDUCAÇÃO POPULAR E COVID-19: RELATO DE EXPERIÊNCIA SOBRE A ATUAÇÃO REMOTA NO PRÉ-UNIVERSITÁRIO POPULAR ALTERNATIVA ${ }^{1}$
}

\author{
POPULAR EDUCATION AND COVID-19: EXPERIENCE REPORT ON REMOTE \\ ACTION IN THE PRÉ-UNIVERSITÁRIO POPULAR ALTERNATIVA
}

\section{Carla Pizzuti Savian², Franciele Delevati $\operatorname{Ben}^{3}$ e Natália Lampert Batista ${ }^{4}$}

\section{RESUMO}

Pensar os impactos da COVID-19 na educação popular se torna um grande desafio, pois a emergência do novo Coronavírus trouxe consigo inúmeros contextos, antes não imaginados, que transformaram significativamente a atuação em sala de aula. Assim, o presente artigo tem como objetivo relatar a experiência de educadoras do Pré-Universitário Popular Alternativa (PUPA), da Universidade Federal de Santa Maria (UFSM), durante o período de março a julho do ano de 2020, visando refletir sobre como essa situação afeta o ensino popular e a formação de educadores vinculados ao PUPA. Metodologicamente, trata-se de um relato de experiência tecido por graduandas de Geografia da referida Universidade. Destaca-se que com o advento do ensino remoto e partindo das experiências aqui apresentadas, considera-se que, para o contexto do PUPA, a pandemia traz severas consequências, pois afastou os estudantes dos seus estudos porque a dificuldade de acesso a infraestrutura básica para as aulas, praticamente, impossibilitou o ensino popular remoto. Conclui-se que a vivência permeada pelas dificuldades impostas pela pandemia trouxe à tona as dificuldades do ensino para uma grande parcela da população brasileira, demostrando a necessidade da formação de professores completar um contexto diverso e capaz de compreender que, em muitos espaços geográficos, a sala de aula, o docente e o discente em conjunto, presencialmente, são a única alternativa possível para a escolarização.

Palavras-chave: Formação de educadores, Ensino de Geografia, Novo Coronavírus.

\section{ABSTRACT}

Thinking about the impacts of COVID-19 on popular education becomes a great challenge, since the emergence of the new Coronavirus brought with it numerous contexts, previously unimagined, that significantly transformed the performance in the classroom. Thus, this article aims to report the experience of educators from the Pré-Universitário Popular Alternativa (PUPA), from Universidade Federal de Santa Maria (UFSM), during the period from March to July of the year 2020, aiming to reflect on how this situation affects popular education and the training of educators linked to PUPA. Methodologically, it is an experience report done by undergraduate students of Geography at that University. It is noteworthy that with the advent of remote education and based on the experiences presented here, it is considered that for the PUPA context, the pandemic has severe consequences, as it distanced students from their studies because of the difficulty in accessing basic infrastructure for classes. It basically made the practice of remote popular education impossible. It is concluded that the experience permeated by the difficulties imposed by the pandemic brought up the difficulties of teaching for a large portion of the Brazilian population. It demonstrated the need for teacher training to

\footnotetext{
${ }^{1}$ Relato de Experiência - UFSM.

${ }^{2}$ Graduanda em Geografia - Universidade Federal de Santa Maria. E-mail: carlasavian@gmail.com

${ }^{3}$ Graduanda em Geografia - Universidade Federal de Santa Maria. E-mail: francielidelevattiben@gmail.com

${ }^{4}$ Pós-doutoranda em Geografia - Universidade Federal de Santa Maria. E-mail: natilbatista3@gmail.com
} 
complete a diverse context and be capable of understanding that, in many geographical spaces, the classroom, the teacher and the student together, in person, are the only possible alternative for schooling.

Keywords: Educator training, Geography teaching, New Coronavirus.

\section{INTRODUÇÃO}

Diante da emergência da Pandemia da COVID-19, além de temáticas diretamente relacionadas à saúde, inúmeras outras questões pertinentes à realidade brasileira passaram a receber holofotes. Dentre esses pontos centrais, a reflexão sobre o acesso e a qualidade do ensino passaram a serem chaves nos debates de professores, estudantes, familiares e toda a comunidade escolar. Como promover um acesso mínimo aos conhecimentos formais em tempos de isolamento social? Obviamente, as Tecnologias de Informação e Comunicação (TIC) foram vistas como solução. Todavia, elas não resolvem as disparidades educacionais e, consequentemente, acentuam ainda mais a percepção das desigualdades existentes em nosso país. Há estudantes e docentes com infraestrutura e possibilidades de manter suas atividades mesmo a distância, porém uma grande parcela da população brasileira é excluída desta alternativa. Assim, que medidas podem colaborar com esse paradoxo, especialmente, frente a iniciativas de educação popular (formais)?

O Pré-Universitário Popular Alternativa (PUPA), da Universidade Federal de Santa Maria (UFSM), que hoje volta suas atividades a preparação de estudantes carentes para o Exame Nacional do Ensino Médio (ENEM) se viu desafiado justamente por esse dilema. Precisava-se manter o vínculo com os estudantes, todavia, por quais meios de isso poderia ser feito?

Destaca-se que, a educação é “um serviço essencial”, um direito de todo cidadão e um dever do Estado (até então). Desse modo, buscaram-se estratégias que mantivessem o processo ensino-aprendizagem, dando importância também ao seu caráter contínuo. A associação não-governamental Todos Pela Educação (2020, p. 6), já destacava no início da Pandemia que havia uma "grande preocupação sobre uma possível paralisação completa do processo de ensino-aprendizagem e de redução dos estímulos que busquem o desenvolvimento cognitivo e socioemocional dos alunos". E, de fato, para alguns estudantes, foi exatamente isso que aconteceu. Desta forma, buscou-se problematizar esse fato, por meio de um relato de experiência no PUPA frente a evidência do ensino remoto.

Nessa perspectiva, devido ao caráter emergencial, novos calendários letivos e planejamentos emergenciais foram traçados e transformaram toda e qualquer expectativa frente a formação de professores que atuam no PUPA. O novo Coronavírus desintegrou as o imaginário dos graduandos docentes e, consequentemente, inseriu-lhes no maior desafio educacional do século, gerado pela, até então, mais significativa Pandemia da contemporaneidade. Sobre a Pandemia, conforme destaca Faria et al (2020), o novo Coronavírus surgiu em Wuhan e ficou rapidamente conhecido por causar infecções respiratórias agudas e graves. "No Brasil, o primeiro caso confirmado pelo vírus foi registrado 
em 26 de fevereiro de 2020" (FARIA et al, 2020, p. 427), fazendo com que inúmeras instituições de ensino mudassem os rumos de seus calendários.

Ressalta-se que a dispersão da COVID-19 ocorre, como afirma Neto (2020), de forma semelhante com o que acontece com as redes de informação no mundo globalizado, sendo (des)territorializadas e sem barreiras de espaço. Faria et al (2020) abordam ainda que o espraiamento do vírus é associado às redes hierárquicas urbanas, espalhando-se de grandes centros urbanos aos pequenos e médios municípios, ou seja, partindo dos espaços luminosos aos espaços opacos, como colocaria Santos (2006).

Em meio a este contexto, em que apenas o isolamento social e a redução da circulação de pessoas pode colaborar para conter o vírus, até que uma vacina ou remédio com eficácia comprovada estejam disponíveis, surge o modelo de aula remota como uma opção viável a manutenção das aulas e do ano letivo, porém não totalmente eficiente, devido a multiplicidade de contexto socioeconômicos vigente em nosso país. É fundamental ressaltar que o ensino remoto tem carácter temporário e emergencial e que, mesmo com as lacunas que apresenta, ainda é uma das poucas alternativas para a manutenção das atividades de ensino. A internet e as TIC passaram a permear de forma significativa o campo da docência e da aprendizagem, porém, mais do que nunca, fica evidente o papel e a importância do professor.

Destaca-se, por outro lado, os desafios que emergem do ensino remoto, pontua-se, especialmente, que exige a qualificação profissional dos docentes para o uso das ferramentas que permitirão o seu exercício profissional, alfabetização e letramento tecnológicos dos mesmos, bem como acesso a infraestrutura e condições básicas para ministrar das aulas. No que se refere aos estudantes, questões semelhantes os afetam. Feltrin e Batista (2017) já destacavam essa relação entre o uso cotidiano das mídias e o seu uso educacional, elucidando que, por mais que o acesso as tecnologias da informação tenha crescido, ele ainda é limitado em termos de funcionalidades, o que não repercute necessariamente em usos coerentes com a finalidade educativa, por isso, é essencial alguém que medie a aprendizagem por meio das TIC. No contexto do PUPA, além das questões gerais há os desafios dos alunos trabalhadores frente ao atual contexto.

Partindo dessas perspectivas, o objetivo deste artigo é relatar uma experiência de educadoras do PUPA, durante o período de março a julho do ano de 2020, visando refletir sobre como essa situação afeta o ensino popular e a formação de educadores vinculados mesmo.

\section{PRÉ-UNiVERSiTÁRIO POPUlAR ALTERNATIVA: EdUCAÇÃo POPUlAR E FORMAÇÃO DOCENTE}

O PUPA é um coletivo de educação popular, constituído como um Projeto de Extensão da UFSM, que visa promover a formação docente de graduandos de diferentes áreas por meio de aulas preparatórias para concursos para o ensino superior, tendo como público alvo estudantes carentes. O projeto visa agregar conhecimentos de forma crítica, reflexiva e aprofundada para os envolvidos 
no processo de ensino-aprendizagem enquanto educandos ou educadores. Ressalta-se que se entende como educação popular uma forma de ensino que propõe o aprimoramento do pensamento crítico e, além disso, valoriza os saberes prévios do educando, assim como valoriza a troca de experiências entre professor-aluno. Desse modo, o ensino possibilita ao aluno uma leitura mais abrangente do mundo em que está inserido, ademais a educação popular valoriza as escolas que primam por uma educação pública, gratuita e de qualidade.

O PUPA busca alcançar esse objetivo por meio de aulas preparatórias permeadas pela educação popular que é caracterizada por práticas educativas que vão de acordo com os pressupostos do educador Paulo Freire (2015). Através das atividades do projeto, esforça-se para além da preparação de aspirantes à universidade que não possuem condições de financiar um curso com foco no ingresso a Instituições de Ensino Superior (IES), mas também busca-se promover experiências para aqueles acadêmicos de licenciatura (e bacharelado) quanto a atuação como educadores, contribuindo assim com a formação de professores na prática e para a prática (UFSM, 2020).

Feltrin (2017) marca que a educação popular tem início em 1459, passando por inúmeros contextos diferenciados e tendo sua hegemonia marcada pela disputa de muitas forças que marcam sua trajetória até a atualidade, em uma perspectiva não linear ou temporal. Já Gomes (2017) menciona que ela ganhou atenção e notoriedade nas décadas de 1950 e 1960 época em que iniciou uma:

[...] mobilização popular na direção da educação que passa a ser vislumbrada como uma possibilidade de inserção na sociedade. Um dos marcos dessa movimentação pedagógica, política e cultural é o projeto de alfabetização desenvolvido por Paulo Freire. (GOMES, 2017, p. 33).

Na paisagem da educação popular proposta por Paulo Freire o ensino contempla a cultura popular, educando às classes populares por meio da valorização dos seus saberes. A leitura de mundo é o ponto inicial para o pensamento de que existe possibilidade de mudança, de diálogo (GOMES, 2017). Freire (2015) traz que ensinar não é somente transferir conhecimento, sendo necessário respeitar a autonomia e a identidade do aluno, promovendo assim uma aprendizagem com sentido e relacionada com a vida, uma aprendizagem que respeita quem o aluno é e quais os seus objetivos de vida.

Destaca-se também que o educador ficou conhecido para além das fronteiras de seu país natal devido ao método de alfabetização de adultos que desenvolveu e que é pautado na pedagogia da libertação ou libertadora. De acordo com Feltrin (2017, p. 127) esse método consiste em “iniciar o processo de alfabetização pelo universo semântico conhecido pelos sujeitos. Encontram-se palavras geradoras que atravessam a vida cotidiana dos alunos e, a partir delas, desenvolve-se um processo de assimilação dos outros conteúdos.” Ou seja, o educador utiliza de conhecimento prévios dos alunos para a construção de novos saberes. Para além disso, "Paulo Freire observou nesse processo que a familiaridade com o conceito que a palavra representava acelerava a aprendizagem de sua escrita, por isso a importância de as palavras geradoras serem retiradas do contexto de vida (família, trabalho, 
gostos) dos sujeitos" (FELTRIN, 2017, p. 127), com essa informação percebemos a importância da troca de experiências e informações entre alunos e professor, algo que o distanciamento também dificulta, principalmente diante de uma turma nova, como é o caso da turma do PUPA.

O PUPA possui uma estrutura de ensino, como já foi explanado, baseada no ensino popular e entre dos benefícios esperados da atuação no mesmo estão a popularização da perspectiva da educação popular, a colaboração na formação do educando e do educador graduando, assim, como a possibilidade de proporcionar vivências em sala de aula através da proposta de educação popular, reforçando a necessidade de entender o contexto do estudantes e de utilizar os seus conhecimentos prévios como fonte da construção de saberes novos (UFSM, 2020).

Para um maior detalhamento deste projeto, na sequência deste do relato de experiência, foi apresentada de que forma ocorreram as inscrições para educadoras do PUPA, o contexto de mudança de sala de aula presencial para a sala de aula online e os métodos que foram utilizados para a disponibilização das aulas na perspectiva de ensino remoto.

\section{SOBRE A OFERTA DE VAGAS PARA EDUCADORES E EDUCANDOS}

Segundo a Pró-Reitoria de Extensão (PRPGP) da UFSM (2020), o PUPA oferta, por ano, aproximadamente 200 vagas em processos seletivos para estudantes que desejam ingressar no ensino superior, via edital de seleção pública. Essas vagas são distribuídas levando em conta critérios socioeconômicos e grau de interesse dos alunos na participação no projeto, tal consideração é realizada mediante entrevista. O curso possui viés popular e funciona através da atuação de acadêmicos de graduação (e pós-graduação) de diversos cursos da Universidade e/ou de outras instituições de ensino superior. Os acadêmicos são monitores, professores e, também, auxiliam na coordenação do curso. Além disso, desenvolvem materiais didáticos que são distribuídos gratuitamente aos estudantes (UFSM, 2020).

A proposta inicial para qual as educadoras e autoras deste artigo se inscreveram, por meio do preenchimento de um formulário disponibilizado no Facebook do Pré-universitário Popular Alternativa, estabelecia a realização de aulas populares e presenciais, as quais aconteceriam no prédio da Antiga Reitoria da Universidade Federal de Santa Maria, localizado na Rua Floriano Peixoto, 1184, $6^{\circ}$ andar, sala 602, Bairro Centro de Santa Maria/RS. Porém, devido ao avanço da crise sanitária causada pelo novo Coronavírus não fora permitido que essa metodologia fosse mantida.

Nesse sentido, o PUPA passou a realizar o ensino remoto, mesmo com significativas dificuldades. Considera-se relevante destacar nesse relato que as oportunidades que o Pré-Universitário Popular Alternativa proporciona aos seus educadores, embora tenha apresentado uma proposta de vivência, acabou proporcionou outra e inserindo suas educadoras e educadores na realidade de todos os professores atualmente, que é a adaptação para a tentativa de um ensino remoto. 
No dia 16 de março de 2020, a UFSM publicou uma nota suspendendo as atividades acadêmicas e administrativas presenciais, em todos os Campus da Instituição devido a expansão do novo Coronavírus. Por causa disso, o PUPA informou aos alunos, educadores e comunidade santa-mariense que iria suspender as atividades (inclusa a aula inaugural do dia 16) por tempo indeterminado. Diante de muitas discussões surge a ideia de adotar o ensino online e remoto, com o objetivo de que ocorra ao menos a disponibilização de material frente ao fato de, na época, não ter sido anunciada uma mudança de data para a realização da prova do ENEM.

\section{SOBRE OS MÉTODOS DE DISPONIBILIZAÇÃO DAS AULAS}

A disponibilização das aulas se deu, por escolha das educadoras, primeiramente pela plataforma Google Classroom, sendo disponibilizadas também pelas redes sociais através de grupos de cada turma que foram criados no WhatsApp e Facebook. Os recursos didáticos adotados pelas educadoras para as aulas foram slides em formatos de pdf. e ppt., atividades via formulário do Google, assim como áudios e vídeos explicando o conteúdo. A escolha dessas opções foram feitas visando o máximo de acessibilidade para alunos que possuem apenas o celular como meio de acesso à internet visto que, segundo a Pesquisa Nacional por Amostra de Domicílios Contínua - Tecnologia da informação e Comunicação (PNAD Contínua TIC, 2018, s/p) cerca de "85\% dos usuários de internet das classes D e E acessam a rede exclusivamente pelo celular, e somente 13\% se conectam tanto pelo aparelho móvel quanto pelo computador". Além disso, sabe-se que "parte dos usuários pós-pago são clientes 'controle', que pagam uma taxa fixa mensal, mas têm um limite, em geral, bastante estrito de tráfego de dados." (BANDEIRA; PASTI, 2020, s/p).

\section{PENSANDO A EXPERIÊNCIA RELATADA...}

O foco do presente relato de experiência é trazer uma perspectiva da formação e qualificação profissional de educadores, assim como do acesso à educação popular por meio do PUPA, durante esse contexto de utilização do ensino remoto. Nele, debateram-se algumas impressões e vivências tecidas em seu âmbito.

O projeto, como já mencionado, visa alcançar alunos de baixa renda, logo com o advento da Pandemia e do ensino remoto o objetivo principal, de gerar uma educação presente, crítica, reflexiva e mediadora entre saberes prévios e novos, deixou de ser alcançado como o esperado pelas educadoras no ingresso no Projeto. Tal fato é alicerçado no fato de que muito estudante não tem acesso a internet e infraestrutura básica para realizarem as aulas online, perdendo, assim, totalmente o contato com 
qualquer forma de aula a ser ministrada frente o distanciamento social. Segundo a PNAD Contínua TIC (2018), uma em cada quatro pessoas brasileiras não têm acesso a internet. Falando em modo geral, de acordo com a última pesquisa feita pela PNAD, isso significa que 46 milhões de brasileiros não acessam as redes ou acessam apenas com fins limitados e esporadicamente (AGÊNCIA BRASIL, 2020).

Ademais:

\begin{abstract}
Quase a metade das pessoas que não têm acesso à rede (41,6\%) diz que o motivo para não acessar é não saber usar .[...] Para 11,8\% delas, o serviço de acesso à internet é caro e para $5,7 \%$, o equipamento necessário para acessar a internet, como celular, laptop e tablet, é caro. (AGÊNCIA BRASIL, 2020, s/p).
\end{abstract}

Partindo disso, além do distanciamento entre educandos e educadores de forma presencial, o acesso desses estudantes as plataformas online, com qualidade, de mostra muito precarizado e praticamente inalcançável. Neste sentido, alguns benefícios que o PUPA visa ofertar, como a vivência em sala de aula como educadora de uma educação popular, é reduzido significativamente no âmbito online. Dando um exemplo de uma turma de Geografia do PUPA, na maior parte das aulas, dos trinta alunos matriculados, apenas dois ou, no máximo, quatro estudantes participam das atividades. Por outro lado, esse contexto remonta as vivências de milhares de professores, que de um momento para outro, se viram obrigados a encontrarem tempo, dinheiro e habilidades para ministrar aula remotamente.

Conforme Menezes (2019, p. 96), ao discutir e defender o óbvio, "Deve-se deixar claro que os desafios cotidianos do professor são fortemente influenciados por uma questão estrutural e, de forma nenhuma, pretende-se recair no reducionismo de culpabilizar o educador pelo quadro atual do ensino básico brasileiro", ou seja, os problemas estruturais do ensino, que já existiam no presencial exposto pela autora, se intensificam no remoto, mas, sobremaneira, não são culpa dos professores ou dos estudantes, mas sim da estrutura e da conjunta que se está vivendo.

Dessa maneira:

É cada dia mais inegável que a pandemia da COVID-19 repercuta de maneiras inimagináveis na rotina das pessoas, assim como nas evidências e fragilidades que impactam a educação de um país. E tais resultados deverão ser cuidadosamente atentados para que impossibilite ainda mais os processos de iniquidades sociais. Cabendo assim, que todos os estágios de atenção social se tornem presentes e atuantes para continuidade ao comprometimento com as demandas socioeducacionais de formar cidadãos críticos, analíticos e científicos e preparados para enfrentar os grandes dilemas da vida contemporânea. (MARQUES, 2020, p. 43).

Outra turma número da Geografia, que também conta com trinta alunos matriculados, tem uma participação de dezenove estudantes na sala de aula do Classroom. Através do gráfico (Figura 1), pode-se perceber, no entanto, que apenas na primeira atividade se obteve um "bom" retorno, sendo a partir desse um declínio de participação que chegou a zero. 
Figura 1 - Número de estudantes que responderam as atividades propostas.

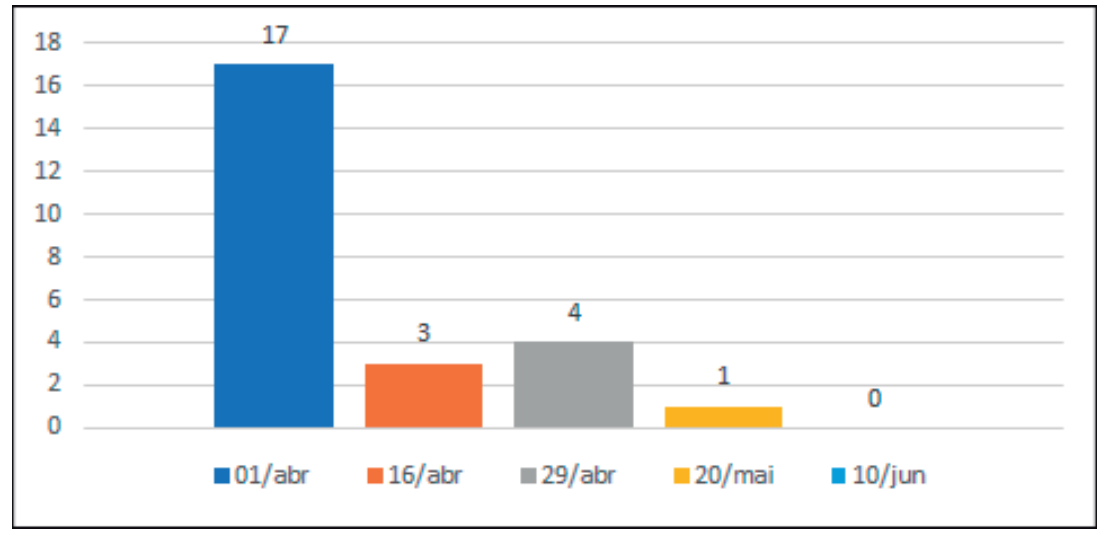

Fonte: organizado pelas autoras, 2020

A educação popular e a proposta do PUPA não se limita a apenas melhorar as notas dos jovens dos setores populares nos vestibulares e no ENEM, tendo a ver também com a democratização do acesso ao ensino. Levando isso em conta, trazemos uma discussão acerca de que apenas a disponibilização de conteúdos como slides, áudios e formulários com questões não possibilitam uma educação problematizadora, que forme um sujeito participativo, ativo na sociedade e crítico e, portanto, pode levar os estudantes que participavam das aulas a se sentirem desmotivados e acabarem abandonando as atividades realizadas (ZYCH; UJIIE, 2008). Em uma educação que visa ser libertadora, a relação educador-educando é constante e a troca de experiências tem muita relevância, algo que foi impossibilitado pela forma de ensino remota e online, enfatizando que o contexto do alternativa são alunos de baixa renda.

Essa impossibilidade de acesso mencionada, que as autoras desse relato acabaram por enfrentar, acarretou a impraticabilidade das aulas, e desse modo, ocasionou também a perda de grande parte das experiências como educadoras pretendidas com a inserção no PUPA. Outras formas de ensino remoto também se tornavam impraticáveis para o contexto, devido às limitações financeiras do projeto e dos próprios estudantes.

Segundo Marques (2020),

Para além dessas questões e atreladas ao processo de implementação de tal alternativa diante do contexto da pandemia pelo COVID-19, cabe destacar que outros elementos merecem reflexão, dentre eles a formação inicial e continuada de professores para a atuação na educação a distância e a adequação do sistema de avaliação em função da modalidade de ensino em um período relativamente curto para se entrar em ação. (MARQUES, 2020, p. 36).

A atuação como educadoras no PUPA foram de expectativas para frustrações geradas pela impossibilidade de atuar devido a pandemia, ou seja, essas expectativas não foram alcançadas e demostraram que a educação, por mais transformadora que seja, necessita de condições mínimas para o seu desenvolvimento. Apenas vontade de estudar, não basta. Também, adquiriu-se conhecimentos diferentes dos planejados, mas que também colaboram na a formação acadêmica e profissional e a 
reflexão sobre a realidade educacional brasileira. Portanto, destaca-se o quão difícil é obter resultados dos alunos de forma remota para contextos de ensino remoto do público alvo do PUPA, assim como, é complexo pensar em uma educação emancipatória da população de baixa renda, utilizando-se de uma ferramenta de difícil acesso para essa mesma população como a internet e infraestrutura de qualidade.

\section{CONCLUSÃo}

A situação de excepcionalidade atual inseriu os educadores e os educandos em um enorme desafio, ocasionado pela pandemia de COVID-19. Os eventos ocorreram de forma muito rápida e impuseram uma adaptação na área da educação, transformando tudo que foi planejado para o ano de 2020. O desafio de levar a sala de aula presencial, por meio da tecnologia, até a casa de cada aluno se tornou algo eminente e cotidiano às práticas educacionais. Nessa perspectiva, a mudança inesperada da sala de aula presencial para a virtual, levou as educadoras do PUPA a enfrentarem a dificuldade de conseguir levar os conhecimentos de aula para os alunos, bem como para se a angústia de necessitar se adaptar a essa nova realidade marcada, sobretudo, pela incerteza do futuro e pelas desigualdades sociais no acesso ao conhecimento.

Logo, com o advento do ensino remoto e partindo das experiências aqui apresentadas, considera-se que, para o contexto do PUPA, a pandemia traz severas consequências, pois afastou os estudantes dos seus estudos porque a dificuldade de acesso a infraestrutura básica para as aulas, praticamente, impossibilitou o ensino popular remoto. Além disso, a nova realidade exige dos educadores e educandos uma adaptação à utilização de tecnologias em suas metodologias de ensino de forma repentina e com pouca ou nenhuma base de formação. Por isso, conclui-se que a vivência permeada pelas dificuldades impostas pela pandemia trouxe a tona as dificuldades do ensino para uma grande parcela da população brasileira, demostrando a necessidade da formação de professores completar um contexto diverso e capaz de compreender que, em muitos espaços geográficos, a sala de aula, o docente e o discente em conjunto, presencialmente, são a única alternativa possível para a escolarização.

\section{AGRADECIMENTOS}

O presente trabalho foi realizado com apoio da Coordenação de Aperfeiçoamento de Pessoal de Nível Superior - Brasil (CAPES) - (PNPD).

\section{REFERÊNCIAS}

BANDEIRA, O; PASTI, A. Como o ensino a distância pode agravar as desigualdades agora. Nexo, 2020. Disponível em: https://bit.ly/3kmE7s5. Acesso em: 28 jul. de 2020. 
FARIA, R. M. DE; ERTHAL, D. B.; COSTA, I. T.; RIZZATTI, M.; SPODE, P. L. C. Difusão da COVID-19 nas grandes estruturas territoriais do estado do Rio Grande do Sul, Brasil. Hygeia Revista Brasileira de Geografia Médica e da Saúde, p. 426-435, 25 jun. 2020. Disponível em: https://bit.ly/36mQkIb Acesso em: 28 jul. de 2020.

FELTRIN, T. Educação Popular no Brasil: forças que concorreram para a formação da Escola Nacional 174 f. (Dissertação de Mestrado). - Universidade Federal de Santa Maria, Santa Maria/RS, 2017.

FELTRIN, T.; BATISTA, N. L. O uso de Tecnologias de Informação e de Comunicação por alunos de $6^{\circ}$ ano de uma escola de periferia como possibilidade pedagógica. Revista Percurso (Online), v. 9 , n. 2, 2017. Disponível em: https://bit.ly/38qX76f. Acesso em: 08/08/2020.

FREIRE, P. Pedagogia da autonomia: saberes necessários à prática educativa. 51. Ed. Rio de Janeiro: Paz e Terra, 2015.

GOMES, T. F. Pré-Universitário Popular Alternativa: formação inicial para a docência entre a educação formal e não formal. 2017. 148f. (Dissertação de Mestrado) - Universidade Federal da Fronteira Sul, Erechim/RS, 2017.

MARQUES, R. A Ressignificação da Educação e o Processo de Ensino e Aprendizagem no Contexto de Pandemia da COVID-19. Boletim de Conjuntura, v. 3, n.7, Boa Vista, 2020. Disponível em: https://bit.ly/32sfaVW. Acesso em 08/08/2020.

MENEZES, V. S. Em tempos de defesa do óbvio: os desafios da docência em Geografia. Terra Livre, v. 2, p. 93-123, 2019. Disponível em: https://bit.ly/2Ia7sJd. Acesso em: 08/08/2020.

NETO, J. M. F. Sobre Ensino, Aprendizagem e a Sociedade da Tecnologia; Por que refletir em tempo de pandemia? Revista Prospectus, v.1, n.1, p. 28-38, 2020. Disponível em: https://bit.ly/3pfbGQb. Acesso em: 01/08/2020.

SANTOS, M. A Natureza do Espaço: Técnica e Tempo, Razão e Emoção. 4. ed. 2. reimpr. - São Paulo: Editora da Universidade de São Paulo, 2006.

TODOS PELA EDUCAÇÃO. Nota Técnica: Ensino a Distância Na Educação Básica Frente à Pandemia da Covid-19. 2020. Disponível em: https://bit.ly/3nchOah. Acesso em: 07/07/2020. 
UNIVERSIDADE FEDERAL DE SANTA MARIA - UFSM. Pró-reitoria de Extensão. Pré-universitário Popular Alternativa. 2020. Disponível em: https://bit.ly/3eHmfGP. Acesso em: 10 jul. de 2020.

ZYCH, A. C.; UJIIE, N. T. O instigador Paulo Freire e os entornos da diversidade. Revista Travessias, v. 2, n. 1, 2008. Disponível em: https://bit.ly/3kceb23. Acesso em: 01/08/2020. 
